\title{
COVID-19: a National Survey on perceived level of knowledge, attitude and practice among frontline healthcare Workers in Nepal
}

Nira Tamang ${ }^{1}$, Punam Rai ${ }^{2}$ Siddhartha Dhungana ${ }^{3}$, Binod Sherchan ${ }^{3}$, Bikash Shah', Prajjwal Pyakurel ${ }^{4}$ and Saroj Rai ${ }^{3^{*}}$ (D)

\begin{abstract}
Background: The aim of this study was to determine the knowledge, attitude and practice (KAP) regarding the COVID-19 among frontline healthcare workers (F-HCWs) working at different hospitals in Nepal and to identify the factors significantly associated with KAP.

Methods: We used a web-based survey, and a convenience sampling method was adopted to collect data from 603 F-HCWs working at different hospitals in Nepal during the first week of June 2020. A self-administered questionnaire was utilized to assess the KAP perceived by the F-HCWs. It was divided into 4-parts consisting of 30items, demographic characteristics (10-items), knowledge (10-items), attitude (5-items), and practice (5-items). It consisted of both multiple-choice questions and Likert scale items questionnaire.

Results: Among the participants, 76\% reported adequate knowledge, 54.7\% reported positive attitude, and 78.9\% reported appropriate practice. Statistically significant differences regarding the perceived level of knowledge among F-HCWs were observed among independent variables, including age, gender, level of education, marital status, profession, work experience, source of information, infection prevention and control (IPC) training, and online course $(p<0.05)$. Similarly, statistically significant differences regarding the attitude among F-HCWs were observed among independent variables, including age, gender, level of education, profession, and online course $(p<0.05)$. Moreover, only 2-independent variables, including the profession and online course, showed statistically significant differences with practice $(p<0.05)$. Pearson correlation analysis showed a significant association between knowledge, attitude and practice at the level of $p=0.01$. The factors significantly associated with adequate knowledge were male gender, nurse and doctor, websites and IPC training. Similarly, factors significantly associated with positive attitude were online course related to COVID-19 only. Moreover, factors significantly associated with appropriate practice were master's degree or above and online course related to COVID-19.

(Continued on next page)
\end{abstract}

\footnotetext{
*Correspondence: mesaroz@outlook.com

${ }^{3}$ Department of Orthopedics and Trauma Surgery, National Trauma Center, National Academy of Medical Sciences, Mahankal, Kathmandu 44600, Nepal Full list of author information is available at the end of the article
}

C C The Author(s). 2020 Open Access This article is licensed under a Creative Commons Attribution 4.0 International License, which permits use, sharing, adaptation, distribution and reproduction in any medium or format, as long as you give appropriate credit to the original author(s) and the source, provide a link to the Creative Commons licence, and indicate if changes were made. The images or other third party material in this article are included in the article's Creative Commons licence, unless indicated otherwise in a credit line to the material. If material is not included in the article's Creative Commons licence and your intended use is not permitted by statutory regulation or exceeds the permitted use, you will need to obtain permission directly from the copyright holder. To view a copy of this licence, visit http://creativecommons.org/licenses/by/4.0/. The Creative Commons Public Domain Dedication waiver (http://creativecommons.org/publicdomain/zero/1.0/) applies to the data made available in this article, unless otherwise stated in a credit line to the data. 
(Continued from previous page)

Conclusions: F-HCWs reported adequate overall knowledge with a positive attitude and adopted the appropriate practice. The experienced F-HCWs with higher education and who received IPC training and online course regarding COVID-19 had better KAP. So, the stakeholders must arrange the educational programs and training for FHCWs for better preparedness tackling with COVID-19.

Keywords: Frontline healthcare workers, COVID-19, Coronavirus disease, Knowledge, Attitude, Practice

\section{Background}

The Coronavirus Disease 2019 (COVID-19) is recently identified as a fatal respiratory problem caused by the Novel Coronavirus subtype SARS-CoV-2 (Severe Acute Respiratory Syndrome Coronavirus 2) [1]. On the last of December 2019, a cluster of pneumonia cases appeared in Wuhan, a highly populated city in Central China, where more than 11 million population reside [2]. The disease is highly contagious and characterized by fever, cough, dyspnoea, fatigue, myalgia, and anosmia [3]. On chest computed tomographic (CT) scan, bilateral lung infiltration with ground glass appearance is evident [4]. The World Health Organization (WHO) stated the Chinese outbreak of Novel coronavirus as a public health emergency on January 30 [5] and named COVID19 on February 11, 2020 [6]. The disease rapidly spread over 114 countries and infected more than 118,000 people, including 4291 deaths, so the WHO declared COVID-19 as a global pandemic on March 11, 2020 [2]. On January 13, 2020, the first case was detected in Nepal, a 32-year-old man studying at Wuhan, who returned to Nepal for winter vacation [7]. He went to the hospital for a cough. For a positive history of travel from the COVID-19 epicenter, and he was investigated for COVID-19. A throat swab was taken and sent to Hongkong for real-time reverse transcriptionpolymerase chain reaction (RT-PCR) and tested positive for COVID-19 [7].

Frontline healthcare workers (F-HCWs), including doctors, nurses, and paramedics, are prone to get infected [8]. A report on the Pan American Health Organization (PAHO) declared that nearly 570,000 COVID-19 infections and at least 2500 death among FHCWs across the region by September 2, 2020 [9]. Similarly, India reported 87,176 contaminations and 573 deaths among F-HCWs by August 29, 2020. However, there still exists a lack of official data reported by the responsible bodies [10]. That has put the F-HCWs at a higher risk of infection, further leading to increased risk to the patients. Meanwhile, Nepal also reported the 1st COVID-19 case among F-HCWs (a nurse) on May 12, 2020, which has increased to 986 F-HCWs with at least 2 deaths on October 13, 2020.

The knowledge, attitude and practice (KAP) regarding pandemic among healthcare workers have been reported differently in different studies [11-15]. COVID-19 infection among local F-HCWs was common at the initial stage of the disease outbreak in Wuhan. However, the infection rate was reduced to nil among the F-HCWs, who were deployed from different provinces to combat COVID-19-the reason they reported having infections at the initial stage was negligence and lack of knowledge [16]. Zhang et al. [13] also reported that the lack of knowledge among F-HCWs is the causative factor for disease infection \& transmission. A similar study from Greece found that a high level of knowledge among healthcare workers was significantly associated with a positive attitude and practice towards preventive health measures [17].

The aim of this study was to determine the knowledge, attitude and practice regarding the COVID-19 among frontline healthcare workers working at different hospitals in Nepal and to identify the factors significantly associated with KAP.

\section{Methods}

\section{Study design and setting}

It is a cross-sectional web-based survey, and a convenience sampling method was adopted. Data were collected using a self-administered questionnaire from the FHCWs working at different hospitals of all seven provinces of Nepal, including private hospitals, government hospitals, and others (semi-government or university hospitals). These hospitals are tertiary care hospitals, where COVID-19 patients are currently being treated.

\section{Study participants}

Registered F-HCWs, including doctors, nurses, and paramedics, working at different hospitals as F-HCWs for COVID-19, were included in this survey. Paramedics, including health assistant (HA) and community medicine assistant (CMA), are trained to provide emergency medical care. Medical students and healthcare workers currently not working in clinical settings or previously participated in a similar study regarding COVID-19 were excluded.

\section{Sample size calculation}

The sample size was calculated from a known population with a formula, 


$$
\text { Sample size }(\mathrm{n})=\frac{\frac{Z^{2} \times \mathrm{p}(1-\mathrm{p})}{e^{2}}}{1+\left(\frac{Z^{2} \mathrm{xp}(1-\mathrm{p})}{e^{2} N}\right)}
$$

Where the population size $(\mathrm{N})$ is 209,552 , including registered doctors, nurses, and paramedics in their respective professional councils. Confidence Level is $95 \%$, population proportion $(p)$ is 0.5 , margin of error $(e)$ is $0.05(5 \%)$, alpha divided by 2 (1-Confidence Level) is 0.025 and $Z$-score is 1.96 . From the above formula, the minimum required sample size $(\mathrm{n})$ calculated was 384 .

\section{Data collection procedure}

The nation had strict lockdown to mitigate disease transmission, so we used a web-based survey to collect data during the first week of June 2020. Potential participants were approached via telephone calls, e-mails, and social media groups, including Viber, WhatsApp, Facebook, etc. A Google Form questionnaire was sent to each of the participants via their e-mails and social media and requested them to fill up and submit. The first page of the Google Form included the consent form that explained the research project overview and participant's confidentiality, making sure that their personal information would remain confidential and they hold the right to withdraw from the study whenever they wish to.

\section{Outcome measures}

A self-administered questionnaire (Additional file) was developed after a thorough review of the literature of previously published papers regarding SARS-COV, MERS-COV, and SARS-COV-2 and following WHO \& CDC guidelines. We used $70 \%$ as a cut-off value for all the questionnaires based on the previously published studies $[15,18,19]$. It consisted of both multiple-choice questions and Likert scale items. We made a short item questionnaire because too long questions might affect the quality of the study. After the development of the questionnaire, a validity and reliability test was performed. The prepared questionnaire was first sent to 5 randomly selected experts from medicine, nursing, and paramedics to give their feedback regarding its contents, simplicity, and significance. Secondly, a pilot study was carried out involving 40 individuals from all the respective departments. A Cronbach's alpha of 0.74 was obtained.

The questionnaire was divided into 4 parts consisting of 30-items, demographic characteristics (10-items), knowledge (10-items), attitude (5-items) and practice (5items). Demographic characteristics consisted of 10 items, including age, gender, level of education, marital status, profession, work experience, source of information, place of work, infection prevention and control
(IPC) training, and online course regarding COVID-19. Knowledge consisted of 10 items, including causative agent, incubation period, mode of transmission, main symptoms, confirmatory diagnosis, high-risk population for severe outcome, preventive measures, current management option, possible complications and mortality rate. It was a multiple-choice question. The correct answer was given 1 point, and an incorrect answer was given 0 point. The score ranged from 0 to 10 . Higher scores denoted better knowledge. While knowledge $\geq 7$ is considered as adequate knowledge, $<7$ is considered as inadequate knowledge.

Attitudeconsisted of a 5-points Likert scale having 5items, including worry about transmitting the virus to family, friend \& society, belief of virus transmission from an asymptomatic patient, belief of IPC from handwashing with soap \& water, belief of development of a vaccine for COVID-19 and belief that COVID-19 would be controlled completely. Participants' response was from 5 to 25 . Higher scores denoted a better attitude. As per $70 \%$ cut-off points, it would become 17.5 , but there was no score in the decimal so, a score of $\geq 18$ was rated as a positive attitude, and $\leq 17$ was rated as a negative attitude. The statement for options strongly agree, agree, neutral, disagree and strongly disagree was scored as 5 , $4,3,2$, and 1 , respectively. The scoring system was just the opposite for worry about transmitting the virus to family, friend \& society.

The practice also consisted of 5-points Likert scale having 5-items, including implementation of 5 moments of hand hygiene with 7 steps, utilization of $60 \%$ alcoholbased hand sanitizer in the absence of soap \& water, wearing of PPE, carefully doffing of PPE and isolation of suspected or infected patients. Participants' response was from 5 to 25 . Higher scores denoted better practice. A similar scoring system obtained for the practice as a score of $\geq 18$ was rated as appropriate, and $\leq 17$ was rated as inappropriate practice. The statement for options was always, often, sometimes, rarely, and never are scored as $5,4,3,2$, and 1 , respectively.

\section{Data management and analyses}

We used Microsoft Excel 2016 and Statistical Package for Social Sciences (SPSS) version 23 for data analyses. One-way ANOVA and Chi-square or Fisher Exact tests were used to analyze continuous data and categorical data, respectively. The descriptive statistical analysis was completed for demographic variables. Continuous data were presented as mean $\pm \mathrm{SD}$, whereas categorical data were presented as number (n) or percentage (\%). Pearson correlation analysis was used to investigate the relationship between knowledge, attitude \& practice among F-HCWs. Binary logistic regression analyses were performed to find 
the factors associated with adequate knowledge, positive attitude, and appropriate practice, and the associations were expressed as adjusted Odds Ratio (aOR) and 95\% Confidence Interval (CI). A $P$-value of $<0.05$ was considered statistically significant.

\section{Results}

Demographic characteristics of participants (Table 1)

A total of $603 \mathrm{~F}-\mathrm{HCW}$ s were involved in this webbased survey. Of them, $64.7 \%$ of the participants were aged 18 to 29 years, and the majority were

Table 1 Demographic Characteristics of the Participants

\begin{tabular}{|c|c|c|}
\hline Variables & Sample $(n=603)$ & Percentage (\%) \\
\hline \multicolumn{3}{|l|}{ Age } \\
\hline 18-29years & 390 & 64.7 \\
\hline 30-49 years & 206 & 34.2 \\
\hline $50+$ years & 7 & 1.2 \\
\hline \multicolumn{3}{|l|}{ Gender } \\
\hline Male & 173 & 28.7 \\
\hline Female & 428 & 71 \\
\hline Others & 2 & 0.3 \\
\hline \multicolumn{3}{|l|}{ Level of Education } \\
\hline Diploma Level & 155 & 25.7 \\
\hline Bachelor's Degree & 307 & 50.9 \\
\hline Master's Degree or Above & 141 & 23.4 \\
\hline \multicolumn{3}{|l|}{ Marital Status } \\
\hline Single & 311 & 51.6 \\
\hline Married & 286 & 47.4 \\
\hline Divorced or Widow & 6 & 1 \\
\hline \multicolumn{3}{|l|}{ Profession } \\
\hline Nurse & 342 & 56.7 \\
\hline Doctor & 158 & 26.2 \\
\hline Paramedics & 103 & 17.1 \\
\hline \multicolumn{3}{|l|}{ Work Experience } \\
\hline Less than 2 years & 198 & 32.8 \\
\hline 2 to 5 years & 186 & 30.8 \\
\hline More than 5 years & 219 & 36.3 \\
\hline \multicolumn{3}{|l|}{ Source of Information } \\
\hline Social Media & 524 & 43.5 \\
\hline Television & 288 & 23.9 \\
\hline Official Websites & 393 & 32.6 \\
\hline \multicolumn{3}{|l|}{ Place of Work } \\
\hline Private Hospital & 335 & 55.5 \\
\hline Government Hospital & 165 & 27.4 \\
\hline Semi-government or University hospitals & 103 & 17.1 \\
\hline \multicolumn{3}{|l|}{ IPC Training } \\
\hline Yes & 264 & 43.8 \\
\hline No & 339 & 56.2 \\
\hline \multicolumn{3}{|l|}{ Online Course } \\
\hline Yes & 172 & 28.5 \\
\hline No & 431 & 71.5 \\
\hline
\end{tabular}

$n$ Number of participants, WHO World Health Organization, CDC Centers for Disease Control \& Prevention, IPC Infection Prevention and Control 
female (71\%). Nearly half of the participants (50.9\%) were bachelor's degree holders and single (51.6\%). The vast majority of the participants were nurses (56.7\%), and a higher proportion (36.3\%) of participants had more than 5 years of work experience. Participants gathered information from various sources, where social media was much used. More than half of the participants (55.5\%) represented the private hospitals. Only $43.8 \%$ of the participants were involved in the IPC training, and only $28.5 \%$ of the participants received the online courses regarding COVID-19.
Perceived level of knowledge, attitude and practice among F-HCWs (Table 2)

\section{Knowledge}

A total of $76 \%$ of the F-HCWs reported adequate knowledge in this survey. Statistically significant differences regarding the perceived level of knowledge among FHCWs were observed among independent variables, including age, gender, level of education, marital status, profession, work experience, source of information, IPC training, and online course $(p<0.05)$. A higher proportion of adequate knowledge was noticed among the FHCWs aged $50+$ years (85.7\%), males (89\%), master's

Table 2 Chi-square test results of demographic variables vs. KAP

\begin{tabular}{|c|c|c|c|c|c|c|c|c|c|c|}
\hline \multirow[t]{2}{*}{ Variables } & & \multicolumn{3}{|c|}{ Knowledge } & \multicolumn{3}{|l|}{ Attitude } & \multicolumn{3}{|l|}{ Practice } \\
\hline & & $\begin{array}{l}\text { Adequate } \\
(n, \%)\end{array}$ & $\begin{array}{l}\text { Inadequate } \\
(n, \%)\end{array}$ & $\begin{array}{l}P \text { - } \\
\text { value }\end{array}$ & $\begin{array}{l}\text { Positive } \\
(n, \%)\end{array}$ & $\begin{array}{l}\text { Negative } \\
(n, \%)\end{array}$ & $\begin{array}{l}P \text { - } \\
\text { value }\end{array}$ & $\begin{array}{l}\text { Appropriate } \\
(n, \%)\end{array}$ & $\begin{array}{l}\text { Inappropriate } \\
(n, \%)\end{array}$ & $\begin{array}{l}P \text { - } \\
\text { value }\end{array}$ \\
\hline \multirow[t]{3}{*}{ Age (years) } & $18-29$ years & $278(71.3)$ & $112(28.7)$ & .002 & $198(50.8)$ & $192(49.2)$ & .012 & $311(79.7)$ & $79(20.3)$ & .255 \\
\hline & $30-49$ years & $174(84.5)$ & $32(15.5)$ & & $126(61.2)$ & $80(38.8)$ & & $158(76.7)$ & $48(23.3)$ & \\
\hline & $50+$ years & $6(85.7)$ & $1(14.3)$ & & $6(85.7)$ & $1(14.3)$ & & $7(100)$ & $0(0)$ & \\
\hline \multirow[t]{3}{*}{ Gender } & Male & $154(89)$ & $19(11)$ & .000 & $105(60.7)$ & $67(39.3)$ & .044 & $129(74.6)$ & $44(25.4)$ & .161 \\
\hline & Female & $303(70.8)$ & $125(29.2)$ & & $223(52.1)$ & 205 (47.9) & & $345(80.6)$ & $83(19.4)$ & \\
\hline & Others & $1(50)$ & $1(50)$ & & $2(100)$ & $0(0)$ & & $2(100)$ & $0(0)$ & \\
\hline \multirow{3}{*}{$\begin{array}{l}\text { Level of } \\
\text { Education }\end{array}$} & Diploma Level & $102(65.8)$ & $53(34.2)$ & .000 & $70(45.2)$ & $85(54.8)$ & .001 & $129(83.2)$ & $26(16.8)$ & .235 \\
\hline & Bachelor's Degree & $230(74.9)$ & $77(25.1)$ & & $165(53.7)$ & $142(46.3)$ & & $241(78.5)$ & $66(21.5)$ & \\
\hline & $\begin{array}{l}\text { Master's Degree or } \\
\text { Above }\end{array}$ & $126(89.4)$ & 15 (10.6) & & $95(67.4)$ & $46(32.6)$ & & $106(75.2)$ & $35(24.8)$ & \\
\hline \multirow[t]{3}{*}{ Marital Status } & Single & $219(70.4)$ & $92(29.6)$ & .006 & $165(53.1)$ & $146(46.9)$ & .374 & $240(77.2)$ & $71(22.8)$ & .584 \\
\hline & Married & $234(81.8)$ & $52(18.2)$ & & $163(57)$ & $123(43)$ & & $231(80.8)$ & $55(19.2)$ & \\
\hline & Divorced or Widow & $5(83.3)$ & $1(16.7)$ & & $2(33.3)$ & $4(66.7)$ & & $5(83.3)$ & $1(16.7)$ & \\
\hline \multirow[t]{3}{*}{ Profession } & Nurse & $242(70.8)$ & $100(29.2)$ & .000 & $172(50.3)$ & $170(49.7)$ & .001 & $285(83.3)$ & $57(16.7)$ & .009 \\
\hline & Doctor & $141(89.2)$ & $17(10.8)$ & & $107(67.7)$ & $51(32.3)$ & & $117(74.1)$ & $41(25.9)$ & \\
\hline & Paramedics & 75 (72.8) & $28(27.2)$ & & $51(49.5)$ & $52(50.5)$ & & $74(71.8)$ & $29(28.2)$ & \\
\hline \multirow{3}{*}{$\begin{array}{l}\text { Work } \\
\text { Experience }\end{array}$} & Less than 2 years & $135(68.2)$ & $63(31.8)$ & .001 & $114(57.6)$ & $84(42.4)$ & .160 & $157(79.3)$ & $41(20.7)$ & .929 \\
\hline & 2 to 5 years & $139(74.7)$ & $47(25.3)$ & & $91(48.9)$ & $95(51.1)$ & & $145(78)$ & $41(22)$ & \\
\hline & More than 5 years & $184(84)$ & $35(16)$ & & $125(57.1)$ & $94(42.9)$ & & $174(79.5)$ & $45(20.5)$ & \\
\hline \multirow{3}{*}{$\begin{array}{l}\text { Source of } \\
\text { Information }\end{array}$} & Social Media & $398(86.9)$ & $126(86.9)$ & .004 & $290(87.9)$ & $234(85.7)$ & .067 & $411(86.3)$ & $113(89.0)$ & .746 \\
\hline & Television & $229(50.0)$ & $59(40.7)$ & & $167(50.6)$ & $121(44.3)$ & & $230(48.3)$ & $58(45.7)$ & \\
\hline & Official Websites & $314(68.6)$ & $79(54.5)$ & & $227(68.8)$ & $166(60.8)$ & & $313(65.8)$ & $80(63.0)$ & \\
\hline \multirow[t]{3}{*}{ Place of Work } & Private Hospital & $246(73.4)$ & 89 (26.6) & .113 & $174(51.9)$ & $161(48.1)$ & .230 & $263(78.5)$ & $72(21.5)$ & .971 \\
\hline & Government Hospital & 135 (81.8) & $30(18.2)$ & & $93(56.4)$ & $72(43.6)$ & & $131(79.4)$ & $34(20.6)$ & \\
\hline & $\begin{array}{l}\text { Semi-government or } \\
\text { University hospitals }\end{array}$ & $77(74.8)$ & $26(25.2)$ & & $63(61.2)$ & $40(38.8)$ & & $82(79.6)$ & $21(20.4)$ & \\
\hline \multirow[t]{2}{*}{ IPC Training } & Yes & $215(81.4)$ & 49 (18.6) & .005 & $156(59.1)$ & 108 (49.8) & .057 & $217(82.2)$ & 47 (17.8) & .083 \\
\hline & No & $243(71.7)$ & $96(28.3)$ & & $174(51.3)$ & 165 (48.7) & & $259(76.4)$ & 80 (23.6) & \\
\hline \multirow{2}{*}{$\begin{array}{l}\text { Online } \\
\text { Course }\end{array}$} & Yes & 142 (82.6) & $30(17.4)$ & .017 & 109 (63.4) & 63 (36.6) & .007 & $150(87.2)$ & $22(12.8)$ & .002 \\
\hline & No & $316(73.3)$ & $115(26.7)$ & & $221(51.3)$ & $210(48.7)$ & & $326(75.6)$ & $105(24.4)$ & \\
\hline
\end{tabular}


degree or above holders (89.4\%), divorced or widow (83.3\%), doctors $(89.2 \%)$, more than 5 years of work experience $(84 \%)$, social media users $(86.7 \%)$, participants working at the government hospitals (81.8\%), and participants who received IPC training (81.4\%) and online courses related to COVID-19 (82.6\%).

\section{Attitude}

Only $54.7 \%$ of the F-HCWs demonstrated a positive attitude. Statistically significant differences regarding the attitude among F-HCWs were observed among independent variables, including age, gender, level of education, profession, and online course $(p<0.05)$. A higher proportion of positive attitude was reported by the F-HCWs aged 50+ years (85.7\%), other gender (100\%), master's degree or above holders $(67.4 \%)$, married (57\%), doctors (67.7\%), less than 2 years of work experience $(57.6 \%)$ social media users $(87.9 \%)$ participants working at semi-government or university hospitals (61.2\%) and participants who received IPC training (59.1\%) and online course related to COVID-19 (63.4\%).

\section{Practice}

Approximately $78.9 \%$ of the F-HCWs implemented appropriate practice. Only 2 independent variables, including the profession and online course, showed statistically significant differences with practice $(p<0.05)$. A higher proportion of appropriate practice was noticed among the F-HCWs aged 50+ years (100\%), other gender (100\%), diploma degree holders $(83.2 \%)$, divorced or widow (83.3\%), nurse (83.3\%), more than 5 years of work experience $(79.5 \%)$, social media users $(86.3 \%)$, participants working at semi-government or university hospitals $(79.6 \%)$, and participants who received IPC training $(82.2 \%)$ and online courses related to COVID-19 (87.2\%).

\section{Correlational analysis between knowledge, attitude and practice among F-HCWs (Table 3)}

In this survey, overall average knowledge was $7.41 \pm 1.43$, attitude was $17.60 \pm 1.97$, and practice was $20.72 \pm 3.72$ regarding COVID-19 among F-HCWs in Nepal. Pearson

Table 3 Correlation analysis of Knowledge, Attitude and Practice

\begin{tabular}{llll}
\hline & & Knowledge & Attitude \\
\hline Attitude & Pearson Correlation & $.112^{* *}$ & \\
& Sig. (2-tailed) & .006 & \\
& $\mathrm{~N}$ & 603 & \\
Practice & Pearson Correlation & $.138^{* *}$ & $.241^{* *}$ \\
& Sig. (2-tailed) & .001 & .000 \\
& $\mathrm{~N}$ & 603 & 603 \\
\hline
\end{tabular}

**. Correlation is significant at the 0.01 level (2-tailed) correlation analysis showed a significant correlation between knowledge, attitude and practice at the level of $p=0.01$.

\section{Factors associated with adequate knowledge, positive attitude and appropriate practice towards COVID-19 (Table 4)}

The factors significantly associated with adequate knowledge were male gender (aOR: 3.66; 95\% CI: 1.97-6.82, $p<0.05$ ), nurse and doctor (aOR: 2.10 ; 95\% CI: 1.18 $3.72 p<0.05$ ), websites (aOR: 1.83; 95\% CI1.13-2.97 $p<0.05$ ) and IPC training (aOR: 1.53; 95\% CI: 1.02-2.31 $p<0.05)$. Similarly, factors significantly associated with positive attitude was online course related to COVID-19 (aOR: 1.49; 95\% CI: 1.02-2.17, $p<0.05$ ) only. Moreover, factors significantly associated with appropriate practice were master's degree or above (aOR: 0.56; 95\% CI: $0.31-$ $1.00, p<0.05)$ and online course related to COVID-19 (aOR: 2.43; 95\% CI: 1.44-4.09, $p<0.05$ ).

\section{Discussion}

It is a web-based national survey involving $603 \mathrm{~F}-\mathrm{HCW}$ working at different hospitals or clinical settings. The vast majority of the participants were female, nurse, and from the private hospital. In this survey, F-HCWs reported adequate knowledge with a positive attitude and adopted the appropriate practice. Factors associated with adequate knowledge were male gender, nurse and doctor, source of information as websites and IPC training, whereas only online course was associated with a positive attitude; similarly, factors associated with the appropriate practice were master's degree or above and online course.

In this survey, around $76 \%$ of F-HCWs illustrated adequate knowledge regarding COVID-19. However, it is relatively higher than the previous study conducted in Uganda [11]. There was only $69 \%$ sufficient knowledge and a bit lower than a Chinese study conducted by Zhang et al. [13] in Henan China, where 89\% of the participants showed sufficient knowledge regarding the COVID-19. Moreover, a similar result was reported by a previous study carried out on MERS among F-HCWs of Saudi Arabia [15]. There are variances in the knowledge of F-HCWs while battling the outbreak in different countries. It could be due to differences in the cut-off points. Olum et al. [11] used $80 \%$ as a cut-off point to determine the level of knowledge, whereas Khan et al. [15] and we used 70\%. In Zhang et al.'s study [13], the reason for a higher proportion of knowledge was probably due to better preparedness for the worst. It might be because the Henan province is a neighbouring province and was one of the severely affected places next to Wuhan. 
Table 4 Factors associated with knowledge, attitude and practice among frontline healthcare workers

\begin{tabular}{|c|c|c|c|c|}
\hline Variables & Parameters & $\begin{array}{l}\text { Knowledge } \\
\text { aOR (95\% Cl) }\end{array}$ & $\begin{array}{l}\text { Attitude } \\
\text { aOR }(95 \% \mathrm{Cl})\end{array}$ & $\begin{array}{l}\text { Practice } \\
\text { aOR }(95 \% \mathrm{Cl})\end{array}$ \\
\hline \multirow[t]{2}{*}{ Age } & $18-29$ years & 1 & 1 & 1 \\
\hline & 30 years or more & $0.80(0.42-1.53)$ & $1.37(0.81-2.32)$ & $0.84(0.43-1.62)$ \\
\hline \multirow[t]{2}{*}{ Gender } & Female \& Others & 1 & 1 & 1 \\
\hline & Male & $3.66(1.97-6.82) *$ & $1.24(0.8-1.91)$ & $0.87(0.52-1.44)$ \\
\hline \multirow[t]{2}{*}{ Marital Status } & Single \& Divorced or Widow & 1 & 1 & 1 \\
\hline & Married & $1.31(0.79-2.15)$ & $0.90(0.60-1.36)$ & $1.68(0.98-2.89)$ \\
\hline \multirow[t]{2}{*}{ Level of Education } & Diploma \& Bachelor's degree & 1 & 1 & 1 \\
\hline & Master's degree or above & $1.95(0.99-3.81)$ & $1.54(0.94-2.52)$ & $0.56(0.31-1.00) *$ \\
\hline \multirow[t]{2}{*}{ Profession } & Paramedics & 1 & 1 & 1 \\
\hline & Nurse \& Doctor & $2.10(1.18-3.72) *$ & $1.43(0.89-2.30)$ & $1.57(0.92-2.68)$ \\
\hline \multirow[t]{2}{*}{ Work Experience } & 5 years or less & 1 & 1 & 1 \\
\hline & More than 5 years & $1.47(0.87-2.49)$ & $0.85(0.56-1.30)$ & $1.11(0.65-1.88)$ \\
\hline \multicolumn{5}{|c|}{ Source of Information } \\
\hline \multirow[t]{2}{*}{ Social Media } & No & 1 & 1 & 1 \\
\hline & Yes & $1.23(0.65-2.31)$ & $1.38(0.80-2.37)$ & $0.74(0.37-1.47)$ \\
\hline \multirow[t]{2}{*}{ Television } & No & 1 & 1 & 1 \\
\hline & Yes & $1.07(0.67-1.72)$ & $1.02(0.68-1.53)$ & $1.17(0.72-1.92)$ \\
\hline \multirow[t]{2}{*}{ Official Websites } & No & 1 & 1 & 1 \\
\hline & Yes & $1.83(1.13-2.97) *$ & $1.49(0.96-2.27)$ & $0.99(0.59-1.65)$ \\
\hline \multirow[t]{2}{*}{ Place of Work } & Private Hospital & 1 & 1 & 1 \\
\hline & Government Hospital \& Semi-government or University hospitals & $1.22(0.81-1.84)$ & $1.23(0.87-1.73)$ & $1.10(0.73-1.67)$ \\
\hline \multirow[t]{2}{*}{ IPC Training } & No & 1 & 1 & 1 \\
\hline & Yes & $1.53(1.02-2.31)^{*}$ & $1.29(0.92-1.81)$ & $1.27(0.83-1.92)$ \\
\hline \multirow[t]{2}{*}{ Online Course } & No & 1 & 1 & 1 \\
\hline & Yes & $1.56(0.97-2.51)$ & $1.49(1.02-2.17) *$ & $2.43(1.44-4.09) *$ \\
\hline
\end{tabular}

aOR Adjusted Odds ratio, $\mathrm{Cl}$ Confidence interval, IPC Infection Prevention and Control; *: Significant at $P \leq 0.05$

Papagiannis et al. [17] reported that the high level of knowledge was significantly associated with positive attitude and practice among F-HCWs. We also had a similar correlation between knowledge, attitude and practice. However, previous studies have reported varying levels of perceived knowledge, attitude, and practice among the F-HCWs. Some studies have reported that the male participants to have a significantly higher knowledge [11]. In contrast, some have reported that female participants have higher knowledge than their male counterparts [12]. Some studies have reported that doctors have better knowledge and a positive attitude than others [13]. However, some reported the nurses to have better practice [14]. In this survey, male participants, doctors, having a master's degree or above showed better knowledge and a positive attitude. Despite having a higher level of education, the F-HCWs did not show any appropriate practice. The reasons for inappropriate practice could be associated with the training they get, the working environment they have, etc. Because most of our hospitals did not provide sufficient sanitizers, PPEs, and even some hospitals, deducted the regular salary of the staff in such a harsh situation.

IPC training and online courses for F-HCWs are essential to update their knowledge and play a vital role in infection prevention [20]. WHO has started training sessions and online classes regarding prevention and control of COVID-19 to increase awareness and preparedness for the F-HCWs [21]. Adequate knowledge, positive attitude, and appropriate practice were present in the participants who attended IPC training and online courses. However, the knowledge was higher in those participants who took IPC training but was not associated with a positive attitude and appropriate practice. Nevertheless, those who took online courses regarding COVID-19 had a positive attitude and appropriate practice. Such results may be due to the fact that training is often organized by the institutions, and irrespective of their interest, participants are requested to attend the training. However, online courses are taken by those 
who have real interest, enthusiasm, and motivation towards the disease. So, they not only give full attention but also try to implement it in their daily activities.

Globally, thousands of F-HCWs are already infected, and hundreds have lost their lives. The risk of COVID19 infection among F-HCWs is higher than the general population [8]. Among the countries, the United States has reported $16 \%$, the Netherlands has $19.6 \%$, Italy has $20 \%$, and Spain has $26 \%$ infection rate among F-HCWs $[17,22]$. Inadequate knowledge increases the risk of infection and might jeopardize their and their family's lives. So, continuous knowledge update for this everchanging pandemic by adequate training or course is crucial for the F-HCWs to tackle the COVID-19. The national and international authorities are continuously providing updates regarding COVID-19. However, social media was the most commonly used source of information than official websites (Ministry of Health and population, WHO, and $\mathrm{CDC}$ ). Although the F-HCWs reported adequate overall knowledge, there were still knowledge gaps among different groups. Our participants mostly used online social media, radio, and television to gather knowledge, and they reported correct answers regarding the symptoms and prevention. Still, most of our participants were not sure about the confirmatory diagnosis as per the standard protocol. That is the defect of relying on only social media, not the standard source of information.

Despite having adequate knowledge, only $54.7 \%$ of FHCWs had a positive attitude in this survey. Similarly, some previously published literature also revealed the lower rate of positive attitude by the F-HCWs in different countries [23, 24]. On the other side, a Chinese study [1] demonstrated a positive attitude among the majority population towards COVID-19. Perhaps, the Chinese were well trained and mentally prepared.

The vast majority of F-HCWs always fear infecting others, including their family, friends, and society [12, $15]$. We also found a similar result of almost $88 \%$ of participants having a fear of infecting others while asking if they were worried about transmitting the virus to their family, friends \& society. However, such fear is entirely normal and acceptable to help the F-HCWs to prepare for the worst during this grim and challenging situation. Despite having a fear of COVID-19, still, F-HCWs displayed appropriate practice. Hand hygiene practice is exceptionally essential. It is quite useful for infection prevention, and even the governments and many other stakeholders are promoting adequate hand hygiene practice. Saqlain et al. [25] reported that hand-washing to be one of the efficient barriers to disease transmission. In this survey, we asked the participants if they believed that hand-washing with soap and water was sufficient for infection prevention; $91.2 \%$ of the F-HCWs chose strongly agreed and agreed. Upon further asking if they are following 5 moments of hand hygiene with 7 steps, $88.4 \%$ of the participants reported often or always, but the remaining participants reported sometimes, rarely, and never. These results mean that our participants have appropriate hand hygiene practices. However, we still believe that hand hygiene is practically the most neglected procedure, and usually, F-HCWs do not follow all the moments and steps. Furthermore, multiple studies supported our findings of having appropriate practice $[13,18]$.

Unfortunately, the shortage of PPEs, such as facemask, face shield, gloves, goggles, and gown, during this COVID-19 crisis are the major problems faced by not only the developing countries like Nepal, but also the developed world like the USA, UK, and Italy. Being a developing country, an adequate supply of PPEs is a tremendous challenge in Nepal. Even if the government or local bodies supplied PPEs, especially the facemask and gown, the quality could not be assessed as most of them are prepared by local factories in an emergency situation. In this survey, only $56.4 \%$ of the participants were using PPEs. Most of them were using facemask, gown, and gloves. A negligible amount of N95 respirators were available for the F-HCWs. Albarrak et al. [18] reported that only $24.2 \%$ were wearing a facemask. It is essential to wear PPE throughout taking care of the patients, especially when performing aerosol-generating procedures such as; intubation, bagging, cardio-pulmonary resuscitation, and nebulization [22].. At the initial stage of the disease outbreak in Wuhan, many local F-HCWs were infected. Upon the arrival of the rescue team from different provinces, the infection to the F-HCWs went down to zero [16]. They mentioned for the infection transmission to the F-HCWs at the inial stage was carelessness, inadequate knowledge, insufficient PPEs, and even improper practice. So, the WHO has also given a particular focus on the correct use of PPEs, including masks, goggles, gloves, and gowns. Additionally, those F-HCWs who have used PPEs have comparatively fewer infection rates [26].

It is a fact that F-HCWs are highly susceptible to the infection, while their constant exposure makes them vectors for disease transmission [13]. Even though the FHCWs have significant roles for infection prevention and disease transmission, it is necessary to follow strict rules of the PPE use, hand-hygiene, and isolation of the patients as per the CDC and WHO guidelines. The government and stakeholders have the responsibility of providing public awareness, regular updates of the infection prevention protocol, and provide adequate IPC training during this pandemic, and adequate logistic supply. Moreover, responsible bodies, including the government and hospitals, must focus on motivational factors, 
including the availability of the resources and provision of salary and incentives to the F-HCWs.

It is a cross-sectional survey, so we could not assess the changes. A web-based survey was conducted to identify the KAP of the F-HCWs working at different hospitals of the nation where they have full access to the internet service. We could not reach out to the place where this facility was not available. Despite these limitations, it is a national survey on the KAP regarding the COVID-19 among F-HCWs in Nepal. This survey would probably be responsible for providing up-to-date information and improve clinical practice among F-HCWs.

\section{Conclusion}

F-HCWs reported adequate overall knowledge with a positive attitude and adopted the appropriate practice. The experienced F-HCWs with a higher level of education and who received IPC training and online courses regarding COVID-19 had better KAP. So, the stakeholders must arrange the educational programs and training for F-HCWs for better preparedness tackling with COVID-19. In addition, they must focus on motivational factors, including the availability of the resources and provision of salary and incentives to the F-HCWs.

\section{Supplementary Information}

The online version contains supplementary material available at https://doi. org/10.1186/s12889-020-10025-8.

Additional file 1. Questionnaire to evaluate the Knowledge, Attitude and Practice among Frontline Healthcare Workers regarding COVID-19.

\section{Abbreviations \\ CDC : Centers for Disease Control \& Prevention; CMA : Community Medicine Assistant; COVID-19 : Coronavirus Disease-2019; CT : Computed Topographic; F-HCW : Frontline Healthcare Worker; HA : Health Assistant; IPC : Infection Prevention and Control; KAP : Knowledge, Attitude and Practice; MERS-CoV : Middle East Respiratory Syndrome Coronavirus; PAHO : Pan American Health Organization; PPE : Personal Protective Equipment; RT-PCR : Reverse Transcription Polymerase Chain Reaction; SARS-CoV : Severe Acute Respiratory Syndrome Coronavirus; SPSS : Statistical Package for Social Sciences; WHO : World Health Organization}

\section{Acknowledgments}

We thank Dr. Sujan Babu Marahatta, Ms. Matina Maharjan, Dr. Niresh Thapa, Ms. llam Gurung, and all the participants for their tremendous support.

\section{Authors' contributions}

All authors have read and approved the manuscript. NT: Study conceptualization, questionnaire development, data collection, and manuscript preparation. PR: Data entry and Data collection. SD: Statistical analysis. BS: Questionnaire development and Final draft approval. BS: Data entry, Data collection, and Final draft approval. PP: Final Revision and Statistical analysis. SR: Study conceptualization, questionnaire development, manuscript preparation, and supervision

\section{Availability of data and materials}

The datasets supporting the conclusion of this article are included within the article. Upon a genuine request, raw data can be provided by the corresponding author.

\section{Ethics approval and consent to participate}

Ethical clearance was obtained from the Ethical Review Board (ERB) of Nepal Health Research Council (ERB Protocol Registration No. 383/2020P) and written informed consent was obtained from participants by asking them to check on an "I agree to participate button" before having access to the questionnaire.

\section{Consent for publication}

Not applicable.

\section{Competing interests}

The authors declare that they have no competing interests.

\section{Author details}

${ }^{1}$ Department of Nursing, Norvic International Hospital, Kathmandu, Nepal. ${ }^{2}$ Kopila Dental Care, Kathmandu, Nepal. ${ }^{3}$ Department of Orthopedics and Trauma Surgery, National Trauma Center, National Academy of Medical Sciences, Mahankal, Kathmandu 44600, Nepal. ${ }^{4}$ B.P. Koirala Institute of Health Sciences, Dharan, Nepal.

Received: 5 July 2020 Accepted: 9 December 2020

Published online: 14 December 2020

\section{References}

1. Zhong B-L, Luo W, Li H-M, Zhang Q-Q, Liu X-G, Li W-T, et al. Knowledge, attitudes, and practices towards COVID-19 among Chinese residents during the rapid rise period of the COVID-19 outbreak: a quick online crosssectional survey. Int J Biol Sci. 2020;16:1745-52.

2. Shi Y, Wang J, Yang Y, Wang Z, Wang G, Hashimoto K, et al. Knowledge and attitudes of medical staff in Chinese psychiatric hospitals regarding COVID19. Brain Behav Immun Health. 2020;4:100064.

3. Singhal T. A review of coronavirus Disease-2019 (COVID-19). Indian J Pediatr. 2020;87:281-6.

4. Lai C-C, Shih T-P, Ko W-C, Tang H-J, Hsueh P-R. Severe acute respiratory syndrome coronavirus 2 (SARS-CoV-2) and coronavirus disease-2019 (COVID19): the epidemic and the challenges. Int J Antimicrob Agents. 2020;55: 105924.

5. Sohrabi C, Alsafi Z, O'Neill N, Khan M, Kerwan A, Al-Jabir A, et al. World Health Organization declares global emergency: a review of the 2019 novel coronavirus (COVID-19). Int J Surg. 2020;76:71-6.

6. Guo Y-R, Cao Q-D, Hong Z-S, Tan Y-Y, Chen S-D, Jin H-J, et al. The origin, transmission and clinical therapies on coronavirus disease 2019 (COVID-19) outbreak - an update on the status. Mil Med Res. 2020;7:11.

7. Bastola A, Sah R, Rodriguez-Morales AJ, Lal BK, Jha R, Ojha HC, et al. The first 2019 novel coronavirus case in Nepal. Lancet Infect Dis. 2020;20:279-80.

8. Nguyen LH, Drew DA, Graham MS, Joshi AD, Guo C-G, Ma W, et al. Risk of COVID-19 among frontline healthcare workers and the general community: a prospective cohort study. Lancet Public Health. 2020;5:e475-83.

9. https://www.paho.org/en/news/2-9-2020-covid-19-has-infected-some-5 70000-health-workers-and-killed-2500-americas-paho.

10. Dey S. https://timesofindia.indiatimes.com/india/over-87k-health-workersinfected-with-covid-19-573-dead/articleshow/77814189.cms.

11. Olum R, Chekwech G, Wekha G, Nassozi DR, Bongomin F. Coronavirus Disease-2019: Knowledge, Attitude, and Practices of Health Care Workers at Makerere University Teaching Hospitals, Uganda. Front Public Health. 2020;8: 181.

12. Asaad A, El Sokkary R, Alzamanan M, El Shafei M. Knowledge and attitudes towards Middle East respiratory sydrome-coronavirus (MERS-CoV) among health care workers in South-Western Saudi Arabia. East Mediterr Health J. 2020;26:435-42.

13. Zhang M, Zhou M, Tang F, Wang Y, Nie H, Zhang L, et al. Knowledge, attitude, and practice regarding COVID-19 among healthcare workers in Henan, China. J Hosp Infect. 2020;105:183-7.

14. Anargh $V$, Singh $H$, Kulkarni A, Kotwal A, Mahen A. Hand hygiene practices among health care workers (HCWs) in a tertiary care facility in Pune. Med J Armed Forces India. 2013;69:54-6. 
15. Khan MU, Shah S, Ahmad A, Fatokun O. Knowledge and attitude of healthcare workers about middle east respiratory syndrome in multispecialty hospitals of Qassim, Saudi Arabia. BMC Public Health. 2014;14: 1281.

16. Li J, Shen X, Shao J, Ze R, Rai S, Hong P, et al. How to manage pediatric orthopaedic patients: strategies to provide safer care during the COVID-19 outbreak in Wuhan, People's Republic of China. J Bone Joint Surg Am. 2020; 102:e86.

17. Papagiannis D, Malli F, Raptis DG, Papathanasiou IV, Fradelos EC, Daniil Z, et al. Assessment of knowledge, attitudes, and practices towards new coronavirus (SARS-CoV-2) of health care professionals in Greece before the outbreak period. Int J Environ Res Public Health. 2020;17:4925.

18. Albarrak Al, Mohammed R, Al Elayan A, Al Fawaz F, Al Masry M, Al Shammari M, et al. Middle East Respiratory Syndrome (MERS): Comparing the knowledge, attitude and practices of different health care workers. J Infect Public Health. 2019;\$1876-0341(19):30239-4.

19. Ayinde OO, Usman AB, Posi A, Gbolahan A. A cross-sectional study on Oyo state health care Worker's knowledge, attitude and practice regarding Corona virus disease 2019 (COVID-19). Adv Infect Dis. 2020;10:6-15.

20. Kanjee Z, Catterick K, Moll AP, Amico KR, Friedland GH. Tuberculosis infection control in rural South Africa: survey of knowledge, attitude and practice in hospital staff. J Hosp Infect. 2011:79:333-8.

21. Bhagavathula AS, Aldhaleei WA, Rahmani J, Mahabadi MA, Bandari DK. Novel Coronavirus (COVID-19) Knowledge and Perceptions: A Survey of Healthcare Workers. preprint. Infect Dis (except HIV/AIDS). 2020. https://doi. org/10.1101/2020.03.09.20033381.

22. Kassie BA, Adane A, Tilahun YT, Kassahun EA, Ayele AS, Belew AK. Knowledge and attitude towards COVID-19 and associated factors among health care providers in Northwest Ethiopia. PLoS One. 2020;15:e0238415.

23. Alkot M, Albouq M, Shakuri M, Subahi M. Knowledge, attitude, and practice toward MERS-CoV among primary healthcare workers in Makkah AlMukarramah: an intervention study. Int J Med Sci Public Health. 2016;5:952.

24. Abolfotouh MA, AlQarni AA, Al-Ghamdi SM, Salam M, Al-Assiri MH, Balkhy $\mathrm{HH}$. An assessment of the level of concern among hospital-based healthcare workers regarding MERS outbreaks in Saudi Arabia. BMC Infect Dis. 2017;17:4.

25. Saqlain M, Munir MM, Rehman SU, Gulzar A, Naz S, Ahmed Z, et al. Knowledge, attitude, practice and perceived barriers among healthcare workers regarding COVID-19: a cross-sectional survey from Pakistan. J Hosp Infect. 2020;105:419-23.

26. Guo X, Wang J, Hu D, Wu L, Gu L, Wang Y, et al. Survey of COVID-19 disease among Orthopaedic surgeons in Wuhan, People's Republic of China. J Bone Jt Surg. 2020;102:847-54.

\section{Publisher's Note}

Springer Nature remains neutral with regard to jurisdictional claims in published maps and institutional affiliations.

Ready to submit your research? Choose BMC and benefit from:

- fast, convenient online submission

- thorough peer review by experienced researchers in your field

- rapid publication on acceptance

- support for research data, including large and complex data types

- gold Open Access which fosters wider collaboration and increased citations

- maximum visibility for your research: over $100 \mathrm{M}$ website views per year

At $\mathrm{BMC}$, research is always in progress.

Learn more biomedcentral.com/submissions 